\title{
Complete Diabetes Cure for Auto Immune Disease and Type 2 Diabetes
}

\section{Disease}

\section{Vivek Kamath*}

Heal the World Organization, Diabetic Healing Care, Karnataka, India

\section{Problem Statement}

Healing Auto Immune Disease Diabetes Type 1/3/LADA (Latent Autoimmune Diabetes of Adulthood) and Type 2 Diabetes

According to Medical science, there is no cure for Auto Immune disease such as Type 1/1.5/3/LADA and for Type 2 patients take insulin or tablets. In other words, our body immune system destroys the pancreatic beta-cells. These beta-cells are required to secrete insulin hormone to control the glucose level in our body. Since there is no insulin secretion happening in Type 1/1.5/3 DM (Diabetes Mellitus), we need to inject insulin from as an injection in our body to control the glucose level. This is going to be a great challenge in energy technique for the healers to protect those pancreatic beta-cells and also energizing pancreas to do the same. These organs are connected to specific energy centers outside our body. Type $2 \mathrm{DM}$ is easy to control if it is a border case diabetic. However, if the root cause of the diabetes is not known then it would be difficult to heal even Type 2 Diabetes. Most of the Type 2 Diabetes is related to psychological factors such as stress, anxiety, insomnia, greed, phobia, extreme jealousy, anger, restlessness, depression, insanity, schizophrenia, parkinson's disease etc. Unless we cure these diseases, we cannot bring down their glucose level. There are number of patients who were suffering from one of the above diseases and when we healed their psychological diseases, their glucose level dropped down drastically. Our workout and diet is not the major factor for the uncontrolled diabetes. It may work for the border case or pre-diabetic cases. Even herbal medicines or foods may help those border cases of diabetes. To conclude, Type 1 needs separate healing techniques to resolve the genetic or low energy organs. In case of Type 2 majority cases are psychological and few cases depend on obesity factor. Below are some of the cases of diabetes patients who reported to us and here are our approach and methodology mentioned how we reduced their glucose level in no time [1,2].

We have healed 2 cases of Diabetes Type 1 patients till date. The first patient was 9 years old boy and his fasting blood glucose was $375 \mathrm{mg} /$ $\mathrm{dL}$ despite of taking 2 doses of insulin per day and his random glucose is normally in the range of $450-500 \mathrm{mg} / \mathrm{dL}$. Another patient was aged 32 years and her fasting blood glucose was not going below $210 \mathrm{mg} / \mathrm{dL}$ despite of taking 3 insulin doses per day.

In the first case we gave Reiki Distant Healing for 21 days and the fasting blood glucose dropped down to $160 \mathrm{mg} / \mathrm{dL}$ and the random glucose level came down to $140 \mathrm{mg} / \mathrm{dL}$.

In the second case, we gave few Mexican Healing, (6 healing sessions) and 5 Reiki distant healing within a week her fasting glucose level dropped down to $119 \mathrm{mg} / \mathrm{dL}$.

\section{Method of Healing}

Our approach and methods followed in both Reiki and Mexican Healing:-

1. Counselled the patients about diabetes and our healing methods to make them aware that it can be healed.

2. Made them believe in themselves, universal energy and have a faith in healers (Energy media).
3. We requested them to follow guidelines during the healing treatment.

4. Healed their Solar-Plexus energy center which is the key energy center for healing diabetes.

5. Energized their pancreas to secrete enough insulin and also healed their digestive system and metabolic system during the healing.

\section{Stress related diabetes healing}

We healed one patient in Dubai, he was having high stress due to his frequent travels and stressful job. We gave him a Reiki Distant Healing therapy for a month to heal his anxiety and stress. He was feeling calmness when initiated the treatment. Within a few days, his glucose level went down drastically.

\section{Obesity related diabetes healing}

We also tried our Reiki Distant healing on one of our patient overseas. She was very obese and also had a high diabetes (Fasting blood glucose was around $230 \mathrm{mg} / \mathrm{dL}$ ). We initially burnt her abdominal fat for few weeks and energized her Pancreas to secrete insulin. Within 2 weeks, her glucose level went down by $50 \%$. She also lost a fat of $4 \mathrm{~kg}$ within a month and feeling comfortable after our healing.

\section{Diabetes complications phobia related healing}

There were some patients who approached us for diabetes healing. These patients were having phobia of diabetes and also phobia about their future. We counselled and brief them how we can heal diabetes. We also cleared some myths they had on diabetes. We were able to bring down their glucose within few days. It is very important for a patient that they need to understand disease in well and counselling is the key part in any healing. We strongly recommend doctors to spend time with the patients and try to understand the root cause of their glucose fluctuation. We also removed their fear/phobia from the subconscious mind using healing technique [3].

\section{Uncontrolled diabetes healing through Reiki and Mexican healing attunement}

We had one patient aged 70 and his random glucose level was quite high around $535 \mathrm{mg} / \mathrm{dL}$. We gave him both Reiki and Mexican Healing attunement and we could see his glucose level went down to $385 \mathrm{mg} /$

*Corresponding author: Vivek Kamath, Reiki Master, Mexican Healing Master, Melchizedek Healer, Crystal Healer and Past Life Regression Therapy Expert, Heal the World Organization, Diabetic Healing Care, Karnataka, India, Tel: +917760749867; E-mail: vivek.kamath@healtheworld.in

Received: September 11, 2018; Accepted: September 24, 2018; Published: September 30, 2018

Citation: Kamath V (2018) Complete Diabetes Cure for Auto Immune Disease and Type 2 Diabetes Disease. Prim Health Care 8: 306. doi: 10.4172/21671079.1000306

Copyright: (C) 2018 Kamath V. This is an open-access article distributed under the terms of the Creative Commons Attribution License, which permits unrestricted use, distribution, and reproduction in any medium, provided the original author and source are credited. 
dL immediately after the attunement. The duration of the attunement process was $30 \mathrm{~min}$. On the next day, we gave the patient a Mexican healing ( 1 session lasting $25 \mathrm{~min}$ ) and his glucose went down by 80 units after 1 healing session. This was like a miracle to see such a drastic drop down in glucose level.

\section{Conclusion}

Diabetes Healing requires thorough understanding of root cause of the disease. It varies from patient to patient.

Type 1/1.5/3/LADA can only be healed through energy technique such as Reiki or Mexican. Healer needs to energize the metabolic system and pancreas of the patient to overcome auto immune disorder.

Type 2 Insulin dependent disease \& Uncontrollable disease- This can be healed through Reiki and Mexican Healing. Healer needs to find out the root cause and heal based on the findings. It could be related to psychological reason. If the healer is able to identify the psychological cause then he/she needs to heal the psychological cause as the first step before healing diabetes $[4,5]$.

Type 2 Border Case Diabetes/Prediabetes/Gestational DiabetesThese cases can be healed using food and diet control or even through herbal medicines or herbal spices.

\section{References}

1. Kamath V (2015) Killer Diabetes-Heal By Yourself.

2. Kamath V (2015) Herbal Remedies for Diabetes: Diabetes.

3. Kamath V (2017) Power of reiki distant healing and its link to quantum physics and telepathy.

4. Kamath V (2017) Power of telepathy vs artificial intelligence.

5. Kamath V (2017) Killer diabetes complication and cure. 